\title{
Radical Quenching by Rosmarinic Acid from Lavandula vera MM Cell Culture
}

\author{
Elena Kovachevaa,*, Milen Georgiev ${ }^{\mathrm{b}}$, Svetlana Pashova ${ }^{\mathrm{c}}$, Maria Angelova ${ }^{\mathrm{c}}$, and \\ Mladenka Ilieva ${ }^{\mathrm{b}}$ \\ a Department of Analytical Chemistry, University of Food Technologies, 26 "Maritza" Blvd., \\ 4002 Plovdiv, Bulgaria. Fax: +359326441 02. E-mail: elkovap@yahoo.com \\ b Department of Microbial Biosynthesis and Biotechnologies - Laboratory in Plovdiv, \\ Institute of Microbiology, Bulgarian Academy of Sciences, 26 "Maritza" Blvd., \\ 4002 Plovdiv, Bulgaria \\ c Department of Mycology, Institute of Microbiology, Bulgarian Academy of Sciences, \\ 26 "Acad. G. Bonchev" Str., Sofia, Bulgaria \\ * Author for correspondence and reprint requests \\ Z. Naturforsch. 61 c, 517-520 (2006); received January 18/February 17, 2006
}

This study was conducted to evaluate the radical scavenging capacities of extracts and preparations from a Lavandula vera MM plant cell culture with different rosmarinic acid content and to compare them with pure rosmarinic and caffeic acids as well. The methods, which were used are superoxide anion and 2,2'-azino-bis(3-ethylbenzothiazoline-6-sulfonic acid) diammonium salt radicals scavenging assays. Results showed that extracts and preparations from Lavandula vera MM possess strong radical scavengers, as the best both radical scavengers appeared to be the fractions with enriched rosmarinic acid content, obtained after ethylacetate fractioning (47.7\% inhibition of superoxide radicals and $14.2 \mu \mathrm{m}$ 6-hydroxy2,5,7,8-tetramethylchroman-2-carboxylic acid equivalents, respectively). These data reveal the possibilities for application of these preparations as antioxidants.

Key words: Rosmarinic Acid, Lavandula vera MM Cell Culture, Superoxide Anion

\section{Introduction}

Recently there has been considerable interest in finding naturally occurring antioxidants with the aim to replace synthetic ones (such as butylated hydroxyanisole and butylated hydroxytoluene), since it was found that the latter possess toxic and mutagenic effects (Akowuah et al., 2004). Sources of natural antioxidants are different plant species. However, utilization of the latter is connected with some difficulties - treatment of huge plant masses, their storage, strong purification systems, influence of seasonal, geographical and agrotechnical factors on the secondary metabolites content etc. An alternative of classical technologies as well as a possible solution of the listed problems are offered plant biotechnologies. In our previous reports, it was found that Lavandula vera MM cell suspension culture is a good producer of rosmarinic acid (RA) and the achieved yields of it are higher in comparison with plant species grown in nature (such as Melissa officinalis, Salvia officinalis, Rosmarinus officinalis) (Georgiev et al., 2004; Pavlov et al., 2005). This led to the possibility for obtain- ing the crude extracts and preparations with enhanced RA content from Lavandula vera MM cell biomass (Georgiev et al., 2006). Further these extracts and preparations were successfully applied for inhibition of oxidation of plant oils and food products (Kovacheva and Georgiev, 2005). The final aim is to use these products as additives in food and cosmetic industries, and with respect to this the extracts and preparations should be characterized through different methods and from different points of view relating to their chemical nature and activity (Frankel and Meyer, 2000).

The purpose of the present report is to determine the total antioxidant activity of extracts and enriched RA preparations from a Lavandula vera MM cell culture using ABTS $^{\bullet+}\left[2,2^{\prime}\right.$-azino-bis(3-ethylbenzothiazoline-6-sulfonic acid) diammonium salt] (whose radical gives information about Trolox equivalent antioxidant capacity) and superoxide radical, which is important for processes in food systems and in living cells as well. 


\section{Materials and Methods}

\section{Chemicals}

Rosmarinic acid (RA), caffeic acid (CA), Trolox (6-hydroxy-2,5,7,8-tetramethylchroman-2-carboxylic acid) and potassium peroxodisulfate were purchased from Aldrich Chemicals (Milwaukee, USA). Superoxide dismutase (SOD) from bovine erythrocytes and nitro blue tetrazolium (NBT) were supplied by Sigma-Aldrich Chemie GmbH (Deisenhofen, Germany). ABTS ${ }^{\bullet+}$ was purchased from Sigma (St. Louis, USA). All other chemicals used in this work were of analytical grade.

\section{Preparation of starting material}

A Lavandula vera $\mathrm{MM}$ plant cell suspension was cultivated in a 3-1 bioreactor (BioFlo 110, New Brunswick, Edison, USA) for $13 \mathrm{~d}$ under conditions previously described (Pavlov et al., 2005). The L. vera MM cell biomass was filtered and frozen, then it was extracted with $50 \%$ ethanol according to Georgiev et al. (2004) and the obtained extract was lyophilized (lyophilizer Alpha 1-2, Martin Christ, Germany). For experiments on radical scavenging activities the lyophilized crude ethanolic extract (E1) and preparations of RA purified by further adsorption on Amberlite XAD-7 (E2) and ethylacetate (E3) were used according to the purification procedure described by Georgiev et al. (2006).

\section{Determination of total phenolic and rosmarinic acid content}

The samples were dissolved in $70 \%$ ethanol and the phenolic content was determined by Folin-Ciocalteu reagent according to the method described by Singleton and Rossi (1965). The total phenolic content was present as gallic acid equivalents.

Rosmarinic acid content in the extract and preparations was determined spectrophotometrically at $327 \mathrm{~nm}$ (spectrophotometer Shimadzu UV/vis 1240 ), as it has been previously described (Georgiev et al., 2004).

\section{ABTS $^{\bullet+}$ radical scavenging activity}

Generation of $\mathrm{ABTS}^{\bullet+}$ was realized through mixing of $7 \mathrm{~mm} \mathrm{ABTS}^{\bullet+}$ (dissolved in PBS with $\mathrm{pH}$ 7.4) with $2.45 \mathrm{~mm}$ potassium peroxodisulfate $(1: 0.5 \mathrm{v} / \mathrm{v})$ at room temperature for $16-17 \mathrm{~h}$. A $1.0 \mathrm{ml}$ solution of $\mathrm{ABTS}^{\circ+}$ (dissolved in ethanol to absorption $0.7 \pm 0.02$ at $734 \mathrm{~nm}$ ) was mixed with
$10 \mu \mathrm{l}$ of samples to be investigated (dissolved in ethanol at the concentration $0.05 \mathrm{mg} / \mathrm{ml}$ ) or with a solution of Trolox also dissolved in ethanol (final concentration $0-20 \mu \mathrm{M}$ was used for standard curve) at $30^{\circ} \mathrm{C}$ after $2 \mathrm{~min}$. The effect of each sample on scavenging $\mathrm{ABTS}^{\bullet+}$ was expressed as Trolox equivalent antioxidant capacity (TEAC) and defined as the concentration of Trolox $(\mu \mathrm{M})$ with equivalent antioxidant activity to a $0.05 \mathrm{mg}$ / $\mathrm{ml}$ sample solution $\left(R^{2}=0.99\right)$.

\section{Superoxide anion radical scavenging activity}

The superoxide anion $\left(\mathrm{O}_{2}^{-\bullet}\right)$ scavenging activity was determined using the method based on the inhibition of NBT-reduction by photochemically generated $\mathrm{O}_{2}^{-}$(Beauchamp and Fridovich, 1971). The sample solution, containing $4.9 \mu \mathrm{g} / \mathrm{ml}$, was added to $56 \mu \mathrm{m}$ NBT, $0.01 \mathrm{~m}$ methionine, $1.17 \mu \mathrm{m}$ riboflavin, $20 \mu \mathrm{m} \mathrm{NaCN}$ and $0.05 \mathrm{~m}$ phosphate buffer, $\mathrm{pH}$ 7.8. The resulting mixture was incubated at $30{ }^{\circ} \mathrm{C}$ and after $6 \mathrm{~min}$ absorbance at $560 \mathrm{~nm}$ was measured. Inhibition of superoxide anion radicals was calculated according to the following equation:

$$
\begin{aligned}
\text { Inhibition }(\%)= & {\left[1-A_{560 \mathrm{~nm}}(\text { sample }) / A_{560 \mathrm{~nm}}\right.} \\
& (\text { control })] \times 100 .
\end{aligned}
$$

For detection of mutually influence of both superoxide dismutase and the investigated samples, commercial SOD from bovine erythrocytes (4780 U/mg protein) was added to the above-mentioned.

\section{Statistical analysis}

All experiments were carried out fourfold; the reported results are the averages of at least three measurements, and the coefficients of variations (CV), expressed as the percentage ratio between standard deviations (SD) and the mean values, were found to be $<15 \%$ in all cases.

\section{Results and Discussion}

Total phenolics and rosmarinic acid content in extracts and preparations of $R A$ from L. vera $M M$

The obtaining of enriched rosmarinic acid preparations from crude extract (E1) was performed following two variants of purification: adsorption on Amberlite XAD-7 and further elution with $80 \%$ ethanolic solution (E2) and through ethylacetate fractioning (E3). Obtained extracts and 


\begin{tabular}{ccccc}
\hline & $\begin{array}{c}\text { Total phenolics } \\
{[\mathrm{mg} \text { gallic acid/g dry weight }]}\end{array}$ & Correlation & $\begin{array}{c}\text { Rosmarinic acid } \\
{[\mathrm{mg} / \mathrm{g} \text { dry weight }]}\end{array}$ & Correlation \\
\hline E1 & $42.3 \pm 4.2$ & 1.0 & $106.3 \pm 5.7$ & 1.0 \\
E2 & $140.2 \pm 15.6$ & 3.3 & $321.4 \pm 11.9$ & 3.0 \\
E3 & $310.1 \pm 21.2$ & 7.3 & $748.6 \pm 9.3$ & 7.0 \\
\hline
\end{tabular}

Table I. Content of total phenolics and rosmarinic acid in crude extract (E1), Amberlite XAD-7 eluate (E2) and ethylacetate fraction (E3) $(\mathrm{X} \pm \mathrm{SD})$.

RA preparations were checked for their phenolics content and rosmarinic acid content as well (Table I). The correlation between E1:E2:E3 expressed as total phenolics and as rosmarinic acid was established and it was found that in purified E2 and E3 preparations the amounts of RA are 3 and 7 times higher compared to the crude extract, and the content of RA in purified preparations reached $32.1 \%$ (in E2 preparations) and $74.9 \%$ (in E3 preparations) (Table I).

\section{$A B T S^{\bullet+}$ radical scavenging activity}

The $\mathrm{ABTS}^{\bullet+}$ radical scavenging is based on decolorization of the blue-green radical, when it reacts with radical scavengers ( $\mathrm{Re}$ et al., 1999; Hu and Skibsted, 2002). The ABTS ${ }^{\bullet+}$ radical decolorization assay is applicable for the study of both water-soluble and lipid-soluble antioxidants $(\operatorname{Re} e t$ $a l ., 1999)$. This method is known for its high sensitivity (Koleva et al., 2001) and is used for determination of total antioxidant activities. Before addition of antioxidants potassium peroxodisulfate was used for forming of $\mathrm{ABTS}^{\bullet+}$ free radicals.

The results (Fig. 1) demonstrated that the pure RA standard and E3 showed almost the same ABTS $^{\bullet+}$ radical scavenging activities, according to the TEAC value (14.53 and $14.19 \mu \mathrm{m}$ Trolox, respectively) versus $19.02 \mu \mathrm{m}$ Trolox of CA. These

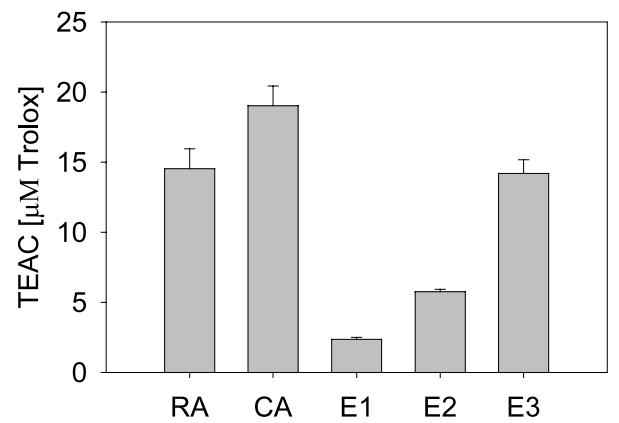

Fig. 1. Total antioxidant activity of rosmarinic acid (RA), caffeic acid (CA) and extracts (E1-E3) expressed as Trolox equivalent (TEAC) in $\mu \mathrm{M}$. Error bars represent standard deviations. results support the statement of Nenadis et al. (2004) that an increased number of hydroxy groups do not necessarily lead to an increase of the TEAC values. Probably the $\mathrm{ABTS}^{\bullet+}$ radical scavenging potential is due to the caffeoil moiety of the RA molecule.

The antioxidant capacities of E1 and E2 extracts were lower (2.36 and $5.76 \mu \mathrm{M}$ Trolox, respectively), which is due to their lower RA content in comparison with ethyl acetate preparations.

\section{Superoxide anion radical scavenging activity}

Superoxide anion radicals $\left(\mathrm{O}_{2}^{-\bullet}\right)$ are generated in vivo, which is dismutated very effectively by different superoxide dismutase forms (SOD, EC 1.15.1.1).

The $\mathrm{O}_{2}^{-}$scavenging capacity of extracts from L. vera $\mathrm{MM}$ and pure compounds (as standards) was investigated and the obtained results are presented in Fig. 2 (black bars). The order of scavenging effectiveness was: E3 (47.7\% inhibition) $\geq$ RA $($ about $46 \%)>$ E1 $(42.5 \%)=\mathrm{CA}(42.3 \%)>$ E2 $(33.2 \%)$. Crude extract from $L$. vera $\mathrm{MM}$ (E1) showed better $\mathrm{O}_{2}{ }^{-}$scavenging activity in comparison with the preparation purified on Amberlite XAD-7 resin (E2), which is higher in RA content.

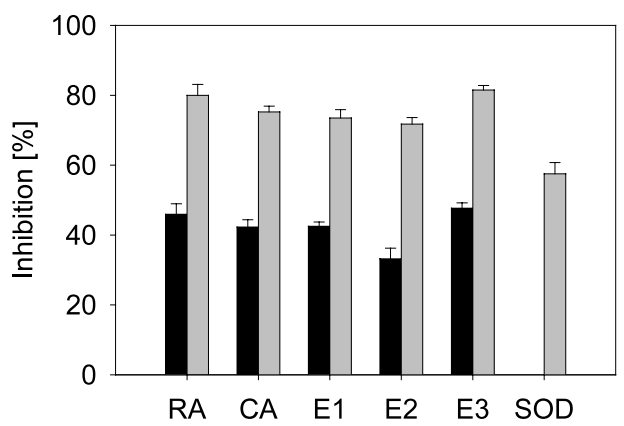

Fig. 2. Superoxide anion radical scavenging activity of rosmarinic acid (RA), caffeic acid (CA) and extracts (E1-E3) from Lavandula vera MM (black bars) and mutual scavenging activity with added superoxide dismutase (SOD) from bovine erythrocytes (grey bars). Error bars represent standard deviations. 
This means that the $\mathrm{O}_{2}{ }^{-\bullet}$ scavenging activities are correlated notably with the RA content of samples, but also with other compounds present in the crude extracts (and not in the column eluate). Perhaps these compounds are sugars, which are known to serve as donors of hydrogen and by this reason they possess antioxidant activities (Akowuah et al., 2004).

For a detailed study of radical scavenging capacity, we investigated the $\mathrm{O}_{2}{ }^{-\bullet}$ scavenging activities of samples at different concentrations, and doseresponse curves were formed (Fig. 3). It was established that at higher concentrations $(13.3-66.6 \mu \mathrm{g} /$ $\mathrm{ml}$ ) the best results were obtained for CA, while RA and ethylacetate fraction E3 showed the same superoxide anion disproportion activities as SOD. These results are in agreement with previous reported results ( $\mathrm{Lu}$ and Foo, 2001).

Further, we investigated the $\mathrm{O}_{2}^{-}$scavenging activities of samples $(4.9 \mu \mathrm{g} / \mathrm{ml})$ in which commercial SOD was added $(5.5 \mathrm{U} / \mathrm{ml})$ (Fig. 2 grey bars). Using this combination the relation between the investigated samples remains the same as without enzyme addition, but in all investigated variants significant inhibition of superoxide radicals was observed. The strongest inhibition of superoxide radicals was observed, when E3 and pure RA were used $(81.5 \%$ and $80 \%$, respectively), which is about $23 \%$ higher compared to the variant when

Akowuah G. A., Zhari I., Norhayati I., Sadikun A. and Khamsah S.M. (2004), Sinensetin, eupatorin, 3'-hydroxy-5,6,7,4'-tetramethoxyflavone and rosmarinic acid contents and antioxidative effect of Orthosiphon stamineus from Malaysia. Food Chem. 87, 559-566.

Beauchamp C. and Fridovich I. (1971), Superoxide dismutase: improved assay and an assay applicable to polyacrylamide gels. Anal. Biochem. 44, 276-287.

Frankel E. N. and Meyer A. S. (2000), The problems of using one-dimensional methods to evaluate multifunctional food and biological systems. J. Sci. Food Agr. 80, 1925-1941.

Georgiev M., Pavlov A., and Ilieva M. (2004), Rosmarinic acid production by Lavandula vera MM cell suspension: Temperature effect. Biotechnol. Lett. 26, $855-856$

Georgiev M., Kovacheva E., Marcheva N., and Ilieva M. (2006), Purification of rosmarinic acid extracts from Lavandula vera MM cell biomass. Food Chem. 94, $111-114$

Hu M. and Skibsted L. H. (2002), Antioxidative capacity of rhizome extract and rhizome knot extract of edible lotus (Nelumbo nuficera). Food Chem. 76, 327-333.

Koleva I. I., Niederlander H. A. G., and van Beek T.A. (2001), Application of ABTS radical cation for select-

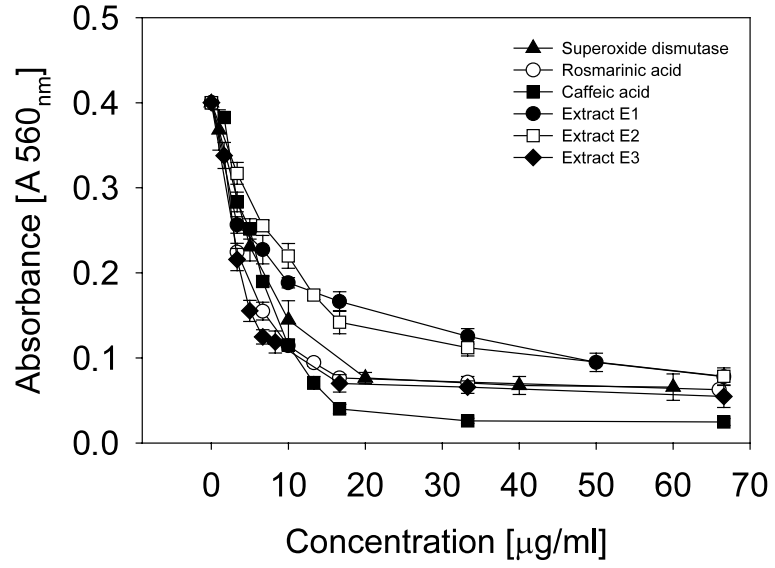

Fig. 3. Dose-response curves of rosmarinic acid, caffeic acid, superoxide dismutase and extracts from Lavandula vera MM against superoxide anion radicals. Error bars represent standard deviations.

only SOD was used. The results outlined the possibilities to use these antioxidants (rosmarinic acid and RA-containing preparations) alone or in combination with SOD effectively in cases, when the cells are exposed to oxidative stress.

\section{Acknowledgements}

The authors acknowledge financial support from University of Food Technologies, Plovdiv, Bulgaria (project 12/04-S-UFT).

ive on-line detection of radical scavengers in HPLC eluates. Anal. Chem. 73, 3373-3381.

Kovacheva E. and Georgiev M. (2005), Extracts from Lavandula vera MM cell culture as antioxidants in food systems. Scientific works of UFT LII (2), 449453 (in Bulgarian).

Lu Y. and Foo Y. (2001), Antioxidant activities of polyphenols from sage (Salvia officinalis). Food Chem. 75, 197-202.

Nenadis N., Wang L.-F., Tsimidou M., and Zhang H.-Y. (2004), Estimation of scavenging activity of phenolic compounds using the ABTS ${ }^{\bullet+}$ assay. J. Agr. Food Chem. 52, 4669-4674.

Pavlov A., Georgiev M., Panchev I., and Ilieva M. (2005), Optimisation of rosmarinic acid production by Lavandula vera MM plant cell suspension in a laboratory bioreactor. Biotechnol. Progr. 21, 394-396.

Re R., Pellegrini N., Proteggente A., Pannala A., Yang M., and Rice-Evans C. (1999), Antioxidant activity applying an improved ABTS radical cation decolorization assay. Free Radical Bio. Med. 26, 1231-1237.

Singleton V. L. and Rossi J. A. (1965), Colorimetry of total phenolics with phosphomolybdic-phosphotungstic acid reagents. Am. J. Enol. Viticult. 16, 144-158. 